\title{
Numerical Study on the Efficiency of Biomass and Municipal Waste Fixed-Bed Co-Gasification
}

\author{
Igor G. Donskoy ${ }^{*}$ \\ ${ }^{1}$ Melentiev Energy Systems Institute of the Siberian Branch of the Russian Academy of Sciences,
} 130 Lermontova st., Irkutsk, Russia 664033

\begin{abstract}
The utilization of combustible waste, such as sewage sludge, can be combined with energy production for small-scale consumers. One of the ways of such utilization can be gasification, which makes it possible to obtain a combustible gas suitable for thermal and electric energy production. The aim of this study is to estimate the efficiency of sewage sludge co-conversion with woody biomass using mathematical model that allows to investigate process characteristics under different process conditions (air stoichiometric ratio, fuel mixture composition, initial moisture of sewage sludge). Dependencies of gasification process characteristics are evaluated and compared with published experimental data. Fixed-bed downdraft process is investigated related to using of wood and sewage sludge mixtures. New results are obtained considering process efficiency dependence on input fuel composition, method is proposed to estimate acceptable fuel mixtures based on agglomeration and efficiency requirements.
\end{abstract}

\section{Introduction}

Sewage sludge is one of the municipal waste types. According to various assessments, several kilograms of the sludge are produced per person annually [1]. Therefore, the issue of its elimination becomes essential for many countries. The main problems of sewage sludge processing are: high moisture, unstable composition and mechanical properties, specific features of thermal behavior including tar formation, sintering of organic mass and ash. The low calorific value of sludge is usually compensated by its combustion in a mixture of quality fuels, such as hydrocarbons, biomass and coal [2].

Combustion is a predominant sludge thermal utilization technology [3]. The rotary kilns, pushing screw conveyors $[4,5]$, and combustion in fluidized bed [6] are often used to prevent sintering in sludge combustion. Combustion generates volatile pollutants that require complex cleaning systems. Gasification is a method of solid fuel conversion producing combustible gas that is usually higher quality fuel than parent material. Biochar may be also a product of gasification, but it is generally considered as unburnt losses. Sewage sludge is known as a material that may agglomerate, so co-gasified fuel is needed for its stable conversion in a fixed bed.

According to thermogravimetric analysis, there are several decomposition stages during combustion of sewage sludge [7-9]. Volatiles yield and charcoal burnout have usually less distinct boundaries compared to other fuels (coal and biomass). In [10], the authors studied a shift of TG-curves because of changes in the oxygen concentration in the air and variation in the $\mathrm{CO} / \mathrm{CO}_{2}$ ratio in the oxidation products.

Co-conversion of sludge and coal under laboratory conditions was investigated in [11], where the authors showed additivity of oxidation of the mixture components. Similar results were obtained in [12]. In [13], the authors found some deviations from additivity. These data however are obtained normally under slow heating rates when the decomposition stages of individual components do not overlap.

The experiments on combustion of single particles of granular sludge were carried out in $[14,15]$. The authors obtained a set of experimental data on combustion kinetics for a wide range of conditions, including those at co-oxidation with coal. The results of the studies were collected in the form of statistical models that allow forecasting the process response within a range of specified values of particle sizes as well as air temperature and flow rate. Oxidation of sewage sludge char particles in drop tube furnace was investigated in [16] with a view to fractional ash composition. In [17], the authors made measurements in the sludge dust-air jet. The relations between the characteristics of jet combustion and individual particles sizes, oxygen concentration and conditions of fuel preparation were obtained.

Gasification of granular sludge with a moisture content of $12 \%$ and ash content of $23 \%$ in the downdraft gasifier was performed in [18]. The authors managed to achieve a steady state with a temperature of 1000 $1100^{\circ} \mathrm{C}$ in the combustion core. The tar and dust content in the raw gas however reached $6-8 \mathrm{~g} / \mathrm{nm}^{3}$. 
Co-pyrolysis of sewage sludge with wood using TGA was studied in [19], non-additivity of pyrolysis kinetics and evolved gas composition was found. In [20], the authors carried out experiments on gasification of wood pellets packing and sewage sludge in batch reactor. Briquettes made of sludge burn with a higher temperature than wood pellets but with lower specific rate. Steady state is achieved at higher values of air stoichiometric ratio (approximately 0.6-0.8).

The co-gasification of sludge with other fuels makes it possible to increase moisture of the processed sludge. For example, in $[21,22]$ the authors consider gasification of woody biomass and sewage sludge with a moisture of $20 \%$. In [21], the authors demonstrate that with a switch from sludge to the mixture with a wood pellet content of $30 \%$, chemical efficiency increases from $20-30 \%$ to 30 $50 \%$. However, the high fraction of sewage sludge in the mixture apart from the deterioration in gas characteristics and fuel conversion can lead to sintering and reduction in the bed permeability $[4,5]$. The obtained gas contains more condensate, and therefore requires additional cleaning.

High moisture, however, can be a favorable circumstance for sludge auto-gasification. With external heating, moisture turns into a gasification agent [23, 24]. This method of gasification was experimentally studied in [25]. The fuel (a mixture of sludge with woodchips) was heated in a screw reactor at a wall temperature of $700-900^{\circ} \mathrm{C}$. The measurements made by the authors indicate that the increase in the fraction of sludge worsens the burning gas characteristics, however it facilitates a more complete conversion of the fuel mixture. Sludge pyrogasification in rotating reactor (for elimination of sintering problems) was performed in [5], where authors report on the $67 \%$ cold gas efficiency, which is achieved owing to the external heat supply, though. In [26], the authors propose an effective method of sludge gasification in water under supercritical conditions.

The experiments on co-gasification of biomass and sewage sludge at the plant with a capacity of nearly 250 $\mathrm{kW}$ demonstrate that heating of the gasification agent enables stable operation of the "gasifier - gas engine" system with an electric efficiency of about 20-23\% [27]. The authors also present a technical-economic analysis of a co-fired thermal power plant that demonstrates the possibility of co-processing in the case where penalties are imposed on emissions although at long-term payback periods.

Single-stage sludge gasification in a fluidized-bed gasifier was studied in [28]. The authors proposed a simplified kinetic model of sludge decomposition and applied it to describe the observed effects. In [29], the authors propose a method for gasification of dry $(2-8 \%$ moisture content) sludge in a two-stage fluidized-bed reactor. The tar products produced in the first stage are absorbed and decomposed in the second stage in the bed of active component (activated carbon, dolomite), which makes it possible to obtain a sufficiently clean gas. In another research [30], the authors managed to reach an additional reduction in tar content in gas, owing to fuel preheating (torrefaction) in a screw feeder. Oxygen concentration (up to 50\%) impact on characteristics of co-gasification process of sewage sludge with straw in bubbling fluidized bed was studied in [31], gas with heating value 4-6 $\mathrm{MJ} / \mathrm{nm}^{3}$ was obtained at cold gas efficiency about $50 \%$.

Mathematical models of sludge gasification processes were developed and used in many papers. Equilibrium thermodynamic models are used most often to estimate transformations of organics [28, 32] and mineral part [33]. In [22, 34], the authors proposed nonstationary zonal and spatially one-dimensional models and used them to study process conditions in fixed-bed gasifiers. One-dimensional model of rotary kiln oxypyrolysis reactor was used in [35] to study effects of staged air supply. CFD-models of fluidized bed gasifiers were developed in [36, 37]. In [38], the authors used several different mathematical models: a thermodynamic model (with constraints on tar production and degree of equilibrium for some reactions) and a three-dimensional CFD-model of physical-chemical processes in a porous medium. Comparison of the research results demonstrates that the degree of model detail slightly affects the integral characteristics of the process, although allows a deeper analysis of the flow and distribution of temperatures in the bed.

The object of the paper is downdraft gasification process of sewage sludge and wood, and the aim is to develop appropriate mathematical model to estimate carbon conversion, gas composition and cold gas efficiency. Proposed model allows obtaining 1D-profiles of temperature and chemical composition in reaction zone. The research also emphasizes the use of this model to determine optimal conditions for the process.

\section{Mathematical model of one- dimensional steady-state reactor}

Consideration is given to a radially homogeneous bed of fuel particles. The process is considered to be steady. The height of reaction zone is $0.25 \mathrm{~m}$, internal diameter of reactor is $0.2 \mathrm{~m}$ (values are given corresponding to work [22]). Fuel flow rate is $10 \mathrm{~kg} / \mathrm{h}$, gasification agent flow rate (air heated to $30^{\circ} \mathrm{C}$ ) is approximately $3-4$ $\mathrm{nm}^{3} / \mathrm{h}$. Fuel represents a mixture of woody particles (with an average size of $2.5 \mathrm{~cm}$ ) and sewage sludge (with the same size of particles). Wood is supposed to be main bed material to provide bed stability, and sewage sludge in a form of dried granules is mixed with wood chips. The composition and properties are presented in Table 1. The equations defining steady-state heat exchange in the fuel bed can be written as follows:

$$
\begin{gathered}
\lambda^{f} \frac{d^{2} T^{f}}{d z^{2}}-C_{p}^{f} J^{f} \frac{d T^{f}}{d z}+\alpha_{1} S_{1}\left(T^{g}-T^{f}\right)+Q^{f}(z)=0, \\
\lambda^{g} \frac{d^{2} T^{g}}{d z^{2}}-C_{p}^{g} J^{g} \frac{d T^{g}}{d z}-\alpha_{1} S_{1}\left(T^{g}-T^{f}\right)-\alpha_{2} S_{2}\left(T^{g}-T^{w}\right)+Q^{g}(z)=0 .
\end{gathered}
$$

Here $T$ - temperature, $\mathrm{K} ; C_{p}$ - heat capacity, $\mathrm{J} / \mathrm{kg} / \mathrm{K}$, $\lambda$ - effective thermal conductivity, $\mathrm{W} / \mathrm{m} / \mathrm{K} ; \alpha-$ heat transfer coefficient, W/m²/K; $J$ - mass flow, $\mathrm{kg} / \mathrm{s} ; S_{1}-$ area of heat exchange between gas and fuel, $\mathrm{m}^{2} ; S_{2}-$ area of heat exchange between gas and wall, $\mathrm{m}^{2} ; Q-$ heat source, $\mathrm{W} ; z$ - spatial coordinate (bed height), $\mathrm{m}$; 
indices $f, g$ and $w$ correspond to fuel, gas and wall.

Table 1 Wood and Sewage Sludge Properties

\begin{tabular}{c|c|c}
\hline \hline Property & Woody biomass & Sewage sludge \\
\hline $\mathrm{W}^{\mathrm{r}}, \%$ & 8.3 & $10-40$ \\
$\mathrm{~A}^{\mathrm{d}}, \%$ & 6.2 & 28.4 \\
$\mathrm{~V}^{\mathrm{daf}}, \%$ & 80 & 76 \\
$\mathrm{C}^{\mathrm{daf}}, \%$ & 47.0 & 47.3 \\
$\mathrm{H}^{\mathrm{daf}}, \%$ & 5.9 & 6.5 \\
$\mathrm{O}^{\mathrm{daf}}, \%$ & 45.2 & 36.9 \\
$\mathrm{~N}^{\mathrm{daf}}, \%$ & 1.0 & 7.0 \\
$\mathrm{~S}^{\mathrm{daf}}, \%$ & 0.8 & 2.3 \\
Particle size, cm & 2.5 & 2.5 \\
\hline \hline
\end{tabular}

These equations together with respective boundary conditions (constants of gas and fuel flow rates at the bed inlet) determine temperature distribution in reactor. Solving these equations also requires the knowledge of functions of the heat sources $Q(z)$. Normally, these functions are determined by kinetics of chemical reactions. This research involves a simplified kineticthermodynamic approach to their calculation [39, 40]. The model combines kinetic and equilibrium relations and allows using robust computational methods of thermodynamics in non-uniform systems with stationary flows of mass and energy [41-43].

To numerically solve the problem, reactor is axially divided into several elements of a small volume. Knowing gas residence time in each of these elements, we can write the heat source function for the chosen $i$-th element as follows:

$$
Q_{i}(z)=\frac{-\Delta H_{i}^{r}}{\tau_{i}}=\frac{\sum h_{j} n_{j}^{i n}-\sum h_{j} n_{j}^{\text {out }}}{\tau_{i}}
$$

Here $\Delta H^{r}$ - change in the enthalpy of components, caused by chemical reactions, $\mathrm{J} ; h_{j}$ - mole enthalpy of the $j$-th component, $\mathrm{J} /$ mole; $\underline{n}_{j}-$ quantity of the $j$-th component, mole; $\tau$ - contact time, s; index in refers to incoming flow, index out - to outgoing flow.

Thus, to determine the function of heat source (or sink), we need to know the change in the component composition of system in a small volume. The change in the chemical composition is calculated in two stages. First, we consider heterogeneous processes: drying, pyrolysis and reactions between charcoal and $\mathrm{O}_{2}, \mathrm{CO}_{2}$ and $\mathrm{H}_{2} \mathrm{O}$.

$$
\begin{aligned}
& \frac{d n_{\mathrm{H}_{2} \mathrm{O}}}{d t}=\beta S_{1}\left(C_{\mathrm{H}_{2} \mathrm{O}}^{e q}-\frac{n_{\mathrm{H}_{2} \mathrm{O}}}{V_{g}}\right) \\
& \frac{d n_{\mathrm{V}}}{d t}=-k_{p y r} n_{\mathrm{V}} \\
& \frac{d n_{\mathrm{C}}}{d t}=-k_{\mathrm{O}_{2}}^{e f f} S_{1} \frac{n_{\mathrm{O}_{2}}}{V_{g}}-k_{\mathrm{CO}_{2}}^{e f f} S_{1} \frac{n_{\mathrm{CO}_{2}}}{V_{g}}-k_{\mathrm{H}_{2} \mathrm{O}}^{e f f} S_{1} \frac{n_{\mathrm{H}_{2} \mathrm{O}}}{V_{g}},
\end{aligned}
$$

Here $V_{g}$ - void volume, $\mathrm{m}^{3} ; \beta$ - mass transfer coefficient, $\mathrm{m} / \mathrm{s} ; C^{e q}$ - equilibrium concentration of water steam, mole $/ \mathrm{m}^{3} ; k_{p y r}$ - pyrolysis rate constant, $\mathrm{s}^{-1} ; n_{V}-$ quantity of volatiles in fuel, mole; $n_{\mathrm{C}}-$ fuel carbon amount, mole; $n_{\mathrm{O}_{2}}, n_{\mathrm{CO}_{2}}, n_{\mathrm{H}_{2} \mathrm{O}},-$ mole quantities of corresponding substances in void volume, mole; $S_{1}-$ area of fuel reaction surface, $\mathrm{m}^{2} ; k^{\text {eff }}$ - effective rate constant of heterogeneous reaction, $\mathrm{m} / \mathrm{s}$ (lower index refers to gasification agent). The effective rate constant of heterogeneous reaction $k^{\text {eff }}$ is determined from the quasi-stationary expression:

$$
k^{e f f}=\frac{1}{\frac{1}{\beta}+\frac{1}{k_{0} e^{-\frac{E}{R T}}}}
$$

Here $k_{0}$ - pre-exponential factor, $\mathrm{m} / \mathrm{s} ; E$ - energy of activation, $\mathrm{J} / \mathrm{mole} ; R$ - universal gas constant, 8.314 $\mathrm{J} / \mathrm{mole} / \mathrm{K}$. Kinetic coefficients of heterogeneous reactions are presented in Table 2 .

Table 2 Kinetic coefficients of woody biomass and sewage sludge reactions

\begin{tabular}{c|cc|cc}
\hline \hline \multirow{2}{*}{ Reaction } & \multicolumn{2}{|c|}{ Woody biomass } & \multicolumn{2}{c}{ Sewage sludge } \\
\cline { 2 - 5 } & $k_{0}$ & $\begin{array}{c}E_{a}, \\
\mathrm{~kJ} / \mathrm{mol}\end{array}$ & $k_{0}$ & $\begin{array}{c}E_{a}, \\
\mathrm{~kJ} / \mathrm{mol}\end{array}$ \\
\hline Pyrolysis & $5.4 \cdot 10^{4}, \mathrm{~s}^{-1}$ & 96 & $2.7 \cdot 10^{6}, \mathrm{~s}^{-1}$ & 120 \\
$\mathrm{C}+\mathrm{O}_{2}$ & $2.4 \cdot 10^{6}, \mathrm{~m} / \mathrm{s}$ & 142 & $1.6 \cdot 10^{6}, \mathrm{~m} / \mathrm{s}$ & 99 \\
$\mathrm{C}+\mathrm{CO}_{2}$ & $1.32 \cdot 10^{7}, \mathrm{~m} / \mathrm{s}$ & 259 & $2.7 \cdot 10^{6}, \mathrm{~m} / \mathrm{s}$ & 218 \\
$\mathrm{C}+\mathrm{H}_{2} \mathrm{O}$ & $9.3 \cdot 10^{5}, \mathrm{~m} / \mathrm{s}$ & 175 & $2.1 \cdot 10^{6}, \mathrm{~m} / \mathrm{s}$ & 158 \\
Tar & $1 \cdot 10^{6}, \mathrm{~s}^{-1}$ & 150 & $1 \cdot 10^{4}, \mathrm{~s}^{-1}$ & 90 \\
decomposition & & & & \\
\hline \hline
\end{tabular}

Heat and mass transfer coefficients are defined as functions of temperature, mean particle size and gas velocity related to widely known correlations for fixed beds. More detailed description of the model could be found in [40, 44, 45]. Whole system of nonlinear algebraic equations was iteratively solved using Newtontype numerical method.

The model was validated by calculations of the conditions of co-gasification of woody biomass and sewage sludge from the work [22]. The calculation results are compiled in Table 3 and show a reasonable agreement between the calculated and experimental values. Deviations are observed mainly in oxygen concentration at the reactor outlet. The experimental oxygen content in gases reaches several percent, which may be explained by air inflows or formation of an inert zone in a small region near the walls.

\section{Optimization of downdraft gasification process of woody biomass and sewage sludge mixtures with different moisture levels}

The constructed model was applied to variant calculations of the process of woody biomass and sewage sludge co-gasification. The range of conditions is: a sewage sludge fraction in the mixture with woody biomass from 0 to $100 \%$ mass (with an increment of $10 \%$ ); an stoichiometric ratio from 0.1 to 0.8 (with an increment of 0.05 ); an initial sewage sludge moisture 
content as-received from 10 to $40 \%$ (with an increment of $10 \%$ ). The calculation results are given below in the form of diagrams which present process characteristics versus the specific air flow rate and fuel composition (Fig. 1). The chemical efficiency surfaces have extrema: with the rising stoichiometric ratio the chemical efficiency increases first owing to fuel oxidation with formation of combustible gases, then it reaches a maximum (that is close to the point of complete conversion of fuel carbon), and then decreases because of oxidation of combustible gases [46].

Table 3Comparison of the modeling results with the experimental data [22]

\begin{tabular}{c|c|c|c|c} 
& \multicolumn{4}{|c}{ Sewage sludge content in mixture, \% } \\
Characteristics of dry gas & 0 & 10 & 20 & 33 \\
$\mathrm{CO}, \%$ vol. & 17.1 & 15.9 & 15.6 & 12 \\
& 16.9 & 16.1 & 15.7 & 15.5 \\
$\mathrm{H}_{2}, \%$ vol. & 17.3 & 17.1 & 16.8 & 13.4 \\
& 18.2 & 17.0 & 16.6 & 10.6 \\
$\mathrm{CH}_{4}, \%$ vol. & 1.7 & 2 & 2.1 & 1.8 \\
& 2.1 & 2.1 & 2.1 & 1.8 \\
$\mathrm{CO}_{2}, \%$ vol. & 11.9 & 12.2 & 12.7 & 12.5 \\
& 14.9 & 14.9 & 14.8 & 13.5 \\
$\mathrm{O}_{2}, \%$ vol. & 1.3 & 1.7 & 1 & 3.4 \\
& 0.0 & 0.0 & 0.0 & 0.0 \\
$\mathrm{Q}, \mathrm{MJ} / \mathrm{nm}^{3}$ & 4.7 & 4.6 & 4.5 & 3.6 \\
& 4.8 & 4.6 & 4.5 & 3.7
\end{tabular}

The upper value is the measured value, the lower value is the calculated value.

Woody biomass without sewage sludge additions is gasified rather effectively, with a maximum chemical efficiency of approximately $70 \%$ (with an stoichiometric ratio of about 0.35 ). Dry sewage sludge (with a moisture of $10 \%$ ) is also converted effectively even without woody biomass additions. However, with the increasing moisture content the isolines of chemical efficiency become more inclined. Sewage sludge with a moisture content of $40 \%$ rather smolders than burns: the maximum efficiency of its conversion is approximately $30 \%$.

The minimum value of the stoichiometric ratio, at which gasification starts, limits thermal stability of the process. As is seen from Fig. 1, this value for woody biomass and dry sewage sludge is equal to about 0.15 . With the increasing moisture, gasification becomes possible at higher specific air flow rates: with a sewage sludge moisture content of $30-40 \%$ the minimum stoichiometric ratio is approximately 0.3 . Such wet fuel is gasified with large heat consumption. Here, the maximum chemical efficiency shifts to higher stoichiometric ratios, as far as at low temperatures the charcoal can be burned with oxidation of a substantial portion of combustible gases.

With a minimum value of the chemical efficiency equal to $50-60 \%$, it becomes possible to determine the maximum sewage sludge fractions in the mixture for different moisture contents (see Table 4). In some cases, the results of mathematical modeling reveal feasibility of sewage sludge gasification without woody biomass additions.
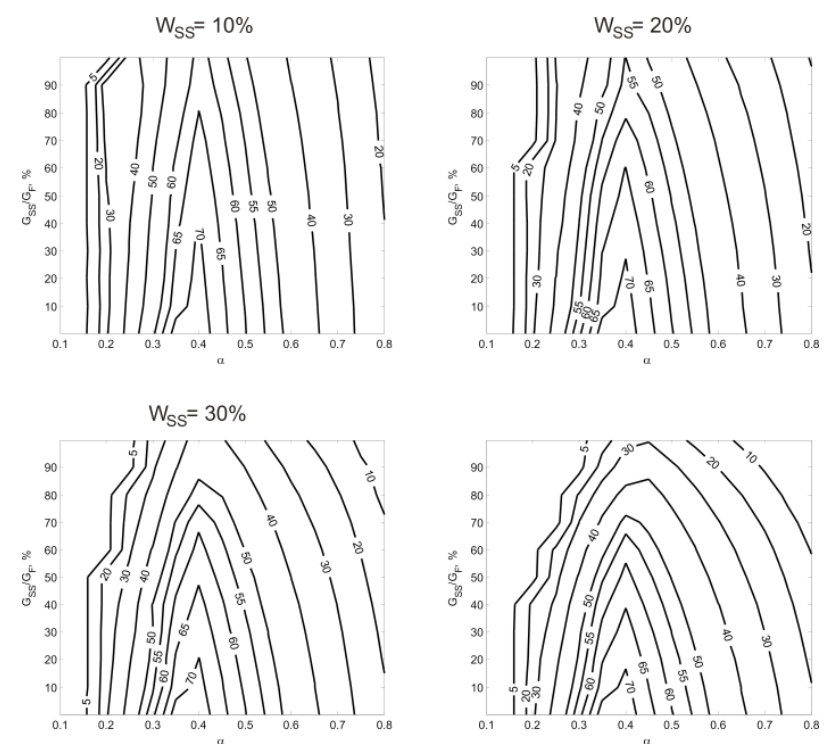

Fig. 1. Cold gas efficiency versus the stoichiometric ratio and the sewage sludge fraction in the mixture with woody biomass.

Table 4Acceptable sewage sludge fraction in the mixture with woody biomass versus its moisture content

\begin{tabular}{c|c|c}
\hline \hline $\begin{array}{c}\text { Minimum chemical } \\
\text { efficiency, \% }\end{array}$ & $\begin{array}{c}\text { Initial sewage } \\
\text { sludge } \\
\text { moisture, \% }\end{array}$ & $\begin{array}{c}\text { Maximum sewage sludge } \\
\text { fraction, \% }\end{array}$ \\
\hline \multirow{3}{*}{60} & 10 & 100 \\
& 20 & 50 \\
& 30 & 40 \\
50 & 10 & 30 \\
& 10 & 100 \\
& 30 & 70 \\
\hline \hline
\end{tabular}

With a sewage sludge moisture content of $40 \%$ its maximum fraction in the mixture with woody biomass is between $30 \%$ and $40 \%$. These values are higher than the known published data on wet sewage sludge conversion. However, agglomeration is not taken into consideration in the mathematical model. In [22], the authors revealed agglomerated particles up to $7-8 \mathrm{~cm}$ in size, which can block the bed. Formation of agglomerated particles is particularly typical of wet fuel. Therefore, the boundaries of effective conditions will differ from those obtained in this study. If the sewage sludge fraction in the mixture is limited at a level of $20-30 \%$ (i.e. assuming that the formed agglomerated particles do not affect gasifier operation at this sewage sludge fraction), the maximum chemical efficiency can be estimated for sewage sludge with different moisture contents in the mixtures with woody biomass. These estimates are presented in Table 5.

The calorific value of the producer gas decreases with the increasing sewage sludge fraction (Fig. 2). For woody biomass this value is about $4 \mathrm{MJ} / \mathrm{nm} 3$, for dry 
sewage sludge - about $3.5 \mathrm{MJ} / \mathrm{nm} 3$, for wet sewage sludge - less than $1 \mathrm{MJ} / \mathrm{nm} 3$. Change in the stoichiometric ratio leads to two extremal values of the calorific value for dry sewage sludge: at low stoichiometric ratios (production of the pyrolysis gas with a high hydrogen content) and close to the point of full carbon conversion (generation of the producer gas with a high $\mathrm{CO}$ content). Pyrolysis of wet sewage sludge is thermally sensitive, therefore at moisture content of $20-40 \%$ the only local extremum value of the calorific value is observed.

Table 5Chemical efficiency of the gasification process with limitation of the sewage sludge mass fraction in the mixture

\begin{tabular}{c|c|c}
\hline \hline $\begin{array}{c}\text { Maximum sewage } \\
\text { sludge fraction, \% }\end{array}$ & $\begin{array}{c}\text { Initial sewage } \\
\text { sludge moisture, } \\
\%\end{array}$ & $\begin{array}{c}\text { Maximum chemical } \\
\text { efficiency, \% }\end{array}$ \\
\hline \multirow{3}{*}{20} & 10 & 67.1 \\
& 20 & 66.0 \\
& 30 & 64.9 \\
& 40 & 63.8 \\
30 & 10 & 67.0 \\
& 20 & 64.6 \\
& 30 & 62.8 \\
\hline \hline
\end{tabular}
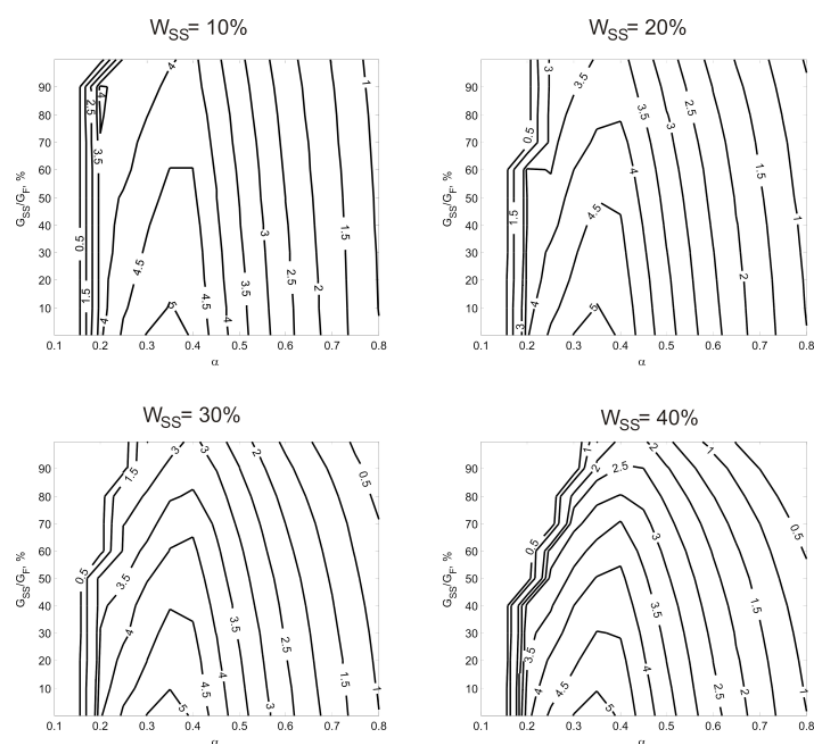

Fig. 2. Calorific value of dry producer gas $(\mathrm{MJ} / \mathrm{Nm} 3)$ versus the stoichiometric ratio and the sewage sludge fraction in the mixture with woody biomass.

Findings presented in the paper may help defining physically allowable level of fuels mixing according to their co-gasification in downdraft gasifier. Regime maps could be useful as a tool for analysis in according to technical and economic efficiency of gasification plant [47].

\section{Conclusions}

Analysis of the results of numeric modeling of coconversion of woody biomass and sewage sludge in a downdraft gasifier shows the following:

1) Provided the bed remains fixed, the sewage sludge gasification with moisture content of $10-20 \%$ can be effective without woody biomass additions. For the sewage sludge with a moisture content of $30-40 \%$ its conversion without woody biomass additions proceeds with low chemical efficiency. The sewage sludge fraction in the mixture depends on the required chemical efficiency and moisture content: for the chemical efficiency of $50-60 \%$ the maximum sewage sludge fraction with a moisture content of $40 \%$ in the mixture of woody biomass amounts to $30-40 \%$. These values are higher than the published experimental data, therefore the model calls for refinement. Presumably, the acceptable sewage sludge fraction will decrease, if the bed blockage is taken into consideration.

2) The maximum cold gas efficiency of cogasification can be evaluated by limiting the sewage sludge fraction in the mixture with woody biomass to $20-30 \%$. The cold gas efficiency is about $60-70 \%$ and decreases with the growing sewage sludge moisture content. The calorific value of wet producer gas in this

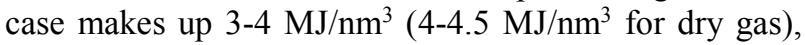
i.e. approximately the same value as for woody biomass without sewage sludge additions.

3) Regime maps presenting process characteristics as functions of input parameters (fuel composition and airfuel ratio) are obtained. Operating these regime maps one can demarcate areas of efficient conversion following different criteria. For example, minimal efficiency and agglomeration avoiding requirements are considered there. Regime maps also could be used in optimization studies of small power plants.

\section{Acknowledgements}

This work was carried out at the Melentiev Energy Systems Institute of Siberian Branch of the Russian Academy of Sciences with financial support of the Russian Foundation for Basic Research (project number 19-08-00744) and using equipment of the multi-access scientific center "High Temperature Circuit".

\section{References}

1. S.S.A. Syed-Hassan, Y. Wang, S. Hu, et al., Renewable and Sustainable Energy Reviews, vol. 80, pp. 888-913, 2017. doi: 10.1016/j.rser.2017.05.262

2. A. Ramos, E. Monteiro, V. Silva, A. Rouboa, Renewable and Sustainable Energy Reviews, vol. 81, pp. 380-398, 2018. doi: 10.1016/j.rser.2017.07.025

3. M. Kacprzak, E. Neczaj, K. Fijalkowski, et al., Environmental Research, vol. 156, pp. 39-46, 2017. doi: 10.1016/j.envres.2017.03.010

4. J. Werther and T.Ogada, Progress in Energy and Combustion Science, vol. 25, pp. 55-116, 1999. doi: 10.1016/S0360-1285(98)00020-3 
5. C. Freda, G. Cornacchia, A. Romanelli, et al., Fuel, vol. 212, pp. 88-94, 2018. doi: 10.1016/j.fuel.2017.10.013

6. J.H. Sung, S.K. Back, B.M. Jeong, et al., Fuel Processing Technology, vol. 172, pp. 79-85, 2018. doi: 10.1016/j.fuproc.2017.12.005

7. D.L. Urban and M.J. Antal Jr., Fuel, vol. 61, pp. 799-806, 1982. doi: 10.1016/0016-2361(82)90306-4

8. L. Nowicki and S. Ledakowicz, Journal of Analytical and Applied Pyrolysis, vol. 110, pp. 220-228, 2014. doi: 10.1016/j.jaap.2014.09.004

9. B. Urych and A. Smolinski, Energy \& Fuels, vol. 30, pp. 4869-4878, 2016. doi: 10.1021/acs.energyfuels.6b00332

10. L.F. Calvo, M. Otero, B.M. Jenkins, et al., Thermochimica Acta, vol. 409, pp. 127-135, 2004. doi: 10.1016/S0040-6031(03)00359-9

11. M.B. Folgueras, R.M. Díaz, J. Xiberta, I. Prieto, Fuel, vol. 82, pp. 2051-2055, 2003. doi: 10.1016/S00162361(03)00161-3

12. M. Otero, L.F. Calvo, M.V. Gil, et al., Bioresource Technology, vol. 99, pp. 6311-6319, 2008. doi: 10.1016/j.biortech.2007.12.011

13. A. Magdziarz and M. Wilk, Journal of Thermal Analysis and Calorimetry, vol. 114, pp. 519-529, 2013. doi: 10.1007/s10973-012-2933-y

14. A. Kijo-Kleczkowska, K. Środa, M. KosowskaGolachowska, et al,. Waste Management, vol. 46, pp. 459-471, 2015. doi: 10.1016/j.wasman.2015.08.015

15. A. Kijo-Kleczkowska, K. Środa, M. KosowskaGolachowska, et al., Fuel, vol. 170, pp. 141-160, 2016. doi: 10.1016/j.fuel.2015.12.026

16. S.B. Liaw, X. Chen, Y. Yu, M. Costa and H. Wu, "Effect of particle size on particulate matter emissions during biosolid char combustion under air and oxyfuel conditions," Fuel, vol. 232, pp. 251-256, 2018. doi: 10.1016/j.fuel.2018.05.163

17. C. Mock, H. Lee, S. Choi and V. Manovic, Fuel, vol. 200, pp. 467-480, 2017. doi: 10.1016/j.fuel.2017.03.055 18. M. Dogru, A. Midilli and C.R. Howarth, Fuel Processing Technology, vol. 75, pp. 55-82, 2002. doi: 10.1016/S0378-3820(01)00234-X

19. J. Zhu, Y. Yang, L. Yang and Y. Zhu, International Journal of Hydrogen Energy, vol. 43, pp. 5463-5472, 2018. doi: 10.1016/j.ijhydene.2018.01.171

20. M. Kim, Y. Lee, J. Park, et al., Waste Management, vol. 49, pp. 204-211, 2016. doi: 10.1016/j.wasman.2016.01.040

21. M. Seggiani, S. Vitolo, M. Puccini and A. Bellini, Fuel, vol. 93, pp. 486-491, 2012. doi: 10.1016/j.fuel.2011.08.054

22.Z. Ong, Y. Cheng, T. Maneerung, et al., AIChE Journal, vol. 61, pp. 2508-2521, 2015. doi: 10.1002/aic. 14836

23. M.P. Järvinen, R. Zevenhoven, E.K. Vakkilainen, Combustion and Flame, vol. 131, pp. 357-370, 2002. doi: 10.1016/S0010-2180(02)00415-7

24. I.G. Donskoi, A.N. Kozlov, D.A. Svishchev and V.A. Shamanskii, Thermal Engineering, vol. 64, pp. 258-264, 2017. doi: 10.1134/S0040601517040024
25. L. Peng, Y. Wang, Z. Lei and G. Cheng, Bioresource Technology, vol. 114, pp. 698-702, 2012. doi: 10.1016/j.biortech.2012.03.079

26. A.A. Vostrikov, O.N. Fedyaeva, A.V. Shishkin, et al., Solid Fuel Chemistry, vol. 42, pp. 384-393, 2008. doi: $10.3103 / \mathrm{S} 0361521908060116$

27.E. Elsner, M. Wysocki, P. Niegodajew and R. Borecki, Applied Energy, vol. 202, pp. 213-227, 2017. doi: 10.1016/j.apenergy.2017.05.148

28. I. Petersen, J. Werther, Chemical Engineering and Processing: Process Intensification, vol. 44, pp. $717-$ 736, 2005. doi: 10.1016/j.cep.2004.09.001

29. T.Y. Mun, J.W. Kim and J.S. Kim, International Journal of Hydrogen Energy, vol. 38, pp. 5226-5234, 2013. doi: 10.1016/j.ijhydene.2012.10.120

30. Y.K. Choi, T.Y. Mun, M.H. Cho and J.S. Kim, Energy, vol. 114, pp. 121-128, 2016. doi: 10.1016/j.energy.2016.07.166

31. M. Niu, B. Jin, Y. Huang, et al., International Journal of Chemical Reactor Engineering, 20170044, 2018. doi: 10.1515/ijcre-2017-0044

32. Y. Sun, Z. Zhang, L. Liu, X. Wang, International Journal of Hydrogen Energy, vol. 41, pp. 5916-5926, 2016. doi: 10.1016/j.ijhydene.2016.02.110

33. Y. Sun, J. Chem, Z. Zhang, Fuel, vol. 220, pp. 318329, 2018. doi: 10.1016/j.fuel.2018.01.142

34. M. Seggiani, M. Puccini and S. Vitolo, Chemical Engineering Transactions, vol. 32, pp. 895-900, 2013. doi: 10.3303/CET1332150

35. F. Montagnaro, C. Tregambi, P. Salatino, et al., Fuel, vol. 231, pp. 468-478, 2018. doi: 10.1016/j.fuel.2018.05.094

36. I. Petersen, J. Werther, Chemical Engineering Science, vol. 60, pp. 4469-4484, 2005. doi: 10.1016/j.ces.2005.02.058

37. Y. Wang, L. Yan, Asia-Pacific Journal of Chemical Engineering, vol. 3, pp. 161-170, 2008. doi: 10.1002/apj.128

38. W.C. Yan, Y. Shen, S. You, et al., Journal of Cleaner Production, vol. 178, pp. 476-493, 2018. doi: 10.1016/j.jclepro.2018.01.009

39. R. Rodrigues, "Modelagem cinética e de equilíbrio combinadas para simulação de processos de gaseificação," PhD Thesis, Universidade Federal do Rio Grande do Sul, 2015.

40. I.G. Donskoy, V.A. Shamansky, A.N. Kozlov, D.A. Svishchev, Combustion Theory and Modelling, vol. 21, pp. 529-559, 2017. doi: 10.1080/13647830.2016.1259505

41. A. Gomez-Barea, B. Leckner, Fuel, vol. 107, pp. 419-431, 2013. doi: 10.1016/j.fuel.2012.09.084

42. P. Kangas, P. Koukkari, M. Hupa, Energy \& Fuels, vol. 28, pp. 6361-6370, 2014. doi: 10.1021/ef501343d 43. A.Z. Mendiburu, J.A. Carvalho Jr., R. Zanzi, et al., Energy, vol. 71, pp. 624-637, 2014. doi: 10.1016/j.energy.2014.05.010

44. I.G. Donskoi, "Process simulation of the cogasification of wood and polymeric materials in a fixed bed," Solid Fuel Chemistry, vol. 52, pp. 121-127, 2018. doi: 10.3103/S0361521918020027 
45. I.G. Donskoy, Bulletin of the Tomsk Polytechnic University. Geo Assets Engineering, vol. 330, no. 2, pp. 7-18, 2019. doi: 10.18799/24131830/2019/2/89

46. M.J. Prins, K.J. Ptasinski, Energy, vol. 30, pp. 9821002, 2005. doi: 10.1016/j.energy.2004.08.010

47. I.G. Donskoy, A.Yu. Marinchenko, A.M. Kler and A.F. Ryzhkov, Thermophysics and Aeromechanics, vol. 22, pp. 639-646, 2015. doi: $10.1134 / \mathrm{S} 0869864315050127$ 